\title{
A Resolução 196/96 e a imposição do modelo biomédico na pesquisa social Dilemas éticos e metodológicos do antropólogo pesquisando o uso de substâncias psicoativas
}

\author{
Edward MacRae ${ }^{1}$ \& Sergio Souza Vidal ${ }^{2}$ \\ Professor da Faculdade de Filosofia e Ciências Humanas - UFBa \\ Graduando em Ciências Sociais - UFBa
}

RESUMO: A Resolução 196/96, instituída pelo Ministério da Saúde com a pretensão de regular os aspectos éticos de qualquer pesquisa "envolvendo seres humanos", ainda não foi plenamente apreciada em suas implicaçôes para os estudos antropológicos. Este artigo ressalta as dificuldades que se apresentam para pesquisas de campo, especialmente as que enfocam atividades ilícitas, tais como o uso de substâncias psicoativas. Esses estudos freqüentemente adotam abordagens etnográficas que pressupõem a ida do pesquisador ao campo e o estabelecimento de relações pessoais entre ele e os sujeitos por meio da participação cotidiana direta em seu meio cultural.

Essa metodologia e a condição ilícita das atividades estudadas demandam considerações éticas específicas, às quais as disposições da Resolução 196/96 não atendem. Algumas áreas problemáticas são: (a) a necessidade de aprovação do projeto por um comitê de ética; (b) a dificuldade para obter consentimento informado quando se trabalha com populaçôes ocultas; (c) "acobertamento", "apologia" ou participação em atos ilegais; (d) a dificuldade em fazer crítica social sem ferir interesses de nenhum dos sujeitos estudados; (e) o anonimato em pesquisas que também tenham caráter de registro histórico. 
Edward MacRae \& Sergio Souza Vidal. A Resolução 196/96...

As especificidades de diferentes disciplinas reforçam a noção de que comissões de ética devem ser setoriais, sob pena de se avaliar questōes diferenciadas segundo padrões somente aplicáveis a algumas delas.

PALAVRAS-CHAVE: ética, etnografia, populações ocultas, substâncias psicoativas, trabalho de campo, ABA.

\section{O uso de psicoativos: uma questão biopsicossocial}

O ser humano vem usando ao longo da história uma série de substâncias ou produtos, atualmente classificados como "drogas" ou substâncias psicoativas, para alterar a maneira de perceber ou de se relacionar com o seu entorno, com finalidades lúdicas, terapêuticas, religiosas e laborativas. Seu uso tem implicado complexas inter-relações entre substâncias, sujeitos e contextos socioculturais, afetando diversos aspectos da vida cotidiana dos inúmeros povos. Ao adaptar as definições adotadas pela Organização Mundial de Saúde para essas substâncias, e outra que Menendez formulou para o álcool, o antropólogo catalão Oriol Romaní considera que drogas seriam

[...] substâncias químicas que se incorporam ao organismo humano, com a capacidade de modificar várias de suas funçōes (percepção, conduta, motricidade etc.), mas cujos efeitos, conseqüências e funções são condicionados acima de tudo pelas definiçôes sociais, econômicas e culturais geradas pelos grupos sociais que as utilizam. (Romaní, 1999, p. 53)

Os estudos que enfocam essas substâncias requerem, portanto, abordagens multidisciplinares que possam dar conta dos seus variados aspectos. Romaní acrescenta que, como no caso das drogas estamos diante de um "fenômeno expressivo", seria mais fácil entendê-las por meio 
de paradigmas que enfatizem mais a compreensão do que a explicação, e que o trabalho científico nesse campo deveria aprofundar os paradigmas relacionais.

Esse imperativo epistemológico esbarra, porém, na tendência atual de "despolitizar" os problemas humanos, apresentando-os como uma questão técnico-científica a ser referida em última instância a suas bases biológico-naturais. Dessa forma, buscar-se-ia um saber neutro, acima das orientaçôes valorativas da sociedade. A institucionalização da medicina científica, da psicologia e da assistência social seria exemplo do desenvolvimento de um saber de técnicos, de uma engenharia social baseada no reducionismo técnico (id., p. 136). Assim, embora tenha se tornado muito difundida e bem-aceita a idéia de que a questão das drogas só pode ser apreendida em toda a sua complexidade por meio de uma abordagem biopsicossocial, as ciências da saúde detêm uma quase hegemonia sobre o discurso considerado legítimo e competente para esse tema. Assim, outras abordagens, como aquelas que privilegiam os aspectos socioculturais da questão, são freqüentemente julgadas pelos critérios da biomedicina, diferentes dos critérios vigentes nas disciplinas das ciências sociais, dentro de cujos padrões foram originalmente concebidos e realizados.

Exemplo disso é o fato de que, nas pesquisas sobre o uso de psicoativos, a adoção de métodos qualitativos, costumeiros na antropologia e em certos ramos da sociologia, é freqüentemente criticada por uma suposta falta de rigor científico e objetividade. Pouco adiantam os argumentos de que, mais uma vez, os defensores dos padróes clássicos da biomedicina estariam ignorando as funçóes constitutivas da cultura na construção e percepção da saúde e da doença. Dessa maneira, para obter reconhecimento institucional, bons financiamentos e, principalmente, legitimidade na comunidade científica e na sociedade em geral para tratar do assunto, os estudos sobre esse tema devem privilegiar os paradigmas epidemiológicos e clínicos. 
Edward MacRae \& Sergio Souza Vidal. A Resolução 196/96...

Outra característica desses trabalhos é que, ainda que se argumente que na relação entre epidemiologia e clínica exista uma "oposição epistemológica” desautorizando a realização de diagnósticos por meio de dados de pesquisas epidemiológicas (Almeida Filho, 1993), o paradigma da epidemiologia-clínica continua sendo muito importante nessa área. O Diagnostic and Statistical Manual of Mental Disorders, editado pela American Psychiatric Association (APA), por exemplo, é o modelo usado por clínicos e pesquisadores do mundo todo para estimar a prevalência de dependentes nos levantamentos domiciliares sobre o uso de drogas em países como Estados Unidos, Grã-Bretanha e Brasil (Samhsa, 1996, 1999; Carlini et al., 2001). Ao mesmo tempo em que a Organização Mundial de Saúde recomenda a utilização da abordagem etnográfica para os estudos sobre substâncias psicoativas como aquela que melhor aproxima-se da cena de consumo e dos vários fatores que a compõem (Rootman et al., 1985 apud Romaní, 1999), continua-se a dar mais valor a pesquisas que privilegiam a abordagem da epidemiologiaclínica, como aquelas que apresentam a prevalência de dependência na população usando como instrumento diagnóstico nove questóes dispostas em um questionário fechado (APA, 1985). Assim, essas pesquisas têm se desviado da abordagem dos fatores socioculturais que plasmam o uso de drogas, buscando, por meio do modelo de causalidade biomédico, relaçôes entre o agente patogênico (droga) e o organismo enfermo (usuário de droga). Dessa maneira, além de deixar de considerar a plenitude do contexto sociocultural em que se dá o uso, procedese à realização de diagnósticos generalizantes sem nenhum contato ou exame pessoal com os indivíduos rotulados clinicamente.

Um exemplo das distorçóes que isso é capaz de acarretar pode ser encontrado nos resultados publicados com base no "I Levantamento Domiciliar Sobre o Uso de Drogas Psicotrópicas”. Nessa pesquisa, para facilitar a comparação dos resultados com os do levantamento domiciliar 
nos Estados Unidos (NHSDA), optou-se por tomar emprestado o modelo para diagnóstico de dependência que utiliza seis dos nove critérios usados pelo manual da APA. Em relação ao uso e à dependência de maconha e de benzodiazepínicos, isso leva a um resultado curioso. Como a prevalência do "uso freqüente" dessas duas substâncias nas 107 maiores cidades do país foi muito baixa, estatisticamente irrelevante, deixouse de apresentá-las, restando para a publicação os dados referentes apenas ao "uso na vida" (6,9\% para maconha e 3,3\% para benzodiazepínicos), muito menos significativo, já que até um único episódio de uso pode ser contabilizado nessa categoria. Porém, ao utilizar os critérios da epidemiologia-clínica dos estudos norte-americanos, chegou-se à estimativa de $1 \%$ de dependentes de maconha e $1,1 \%$ de dependentes de benzodiazepínicos (Carlini et al., 2001, pp. 67-8). Assim, fica patente uma certa incongruência no modelo explicativo da epidemiologia-clínica para o uso de drogas ao se sugerir a possibilidade de ter dependentes sem haver uso freqüiente. Isso seria conseqüência da opção por uma ferramenta diagnóstica da epidemiologia-clínica sem levar em consideração suas inconsistências teórico-metodológicas.

Mesmo quando a biomedicina lança mão de alguns conceitos e métodos das ciências sociais, privilegia o positivismo e o funcionalismo sociológico, deixando de atentar para as tensões e os conflitos na sociedade, as determinaçôes sociais da saúde/doença, assim como os aspectos da medicina como produção cultural (Minayo, 1999, pp. 39-49).

Isso leva a importantes perdas na compreensão do fenômeno e na eficácia em responder a ele quando se aplicam esses modelos de análise ao uso e efeito de psicoativos, já que a ação farmacológica das substâncias não pode ser tratada em separado de fatores com determinantes de natureza sociocultural, tais como padrôes de uso.

De fato, as abordagens da questão das drogas não podem deixar de tratar de temas como: (a) os significados atribuídos ao uso e a sua persis- 
Edward MacRae \& Sergio Souza Vidal. A Resolução 196/96...

tência; (b) os distintos usos e as formas de vida correlatos; (c) as expectativas sobre os efeitos do uso dessas substâncias; (d) a identidade social do "usuário", do "toxicômano", do "traficante" etc.; (e) o funcionamento do comércio ilegal; (f) o funcionamento das instituições assistenciais, suas práticas e ideologias, e como ajudam a configurar o "problema".

Temas como esses necessitam não somente abordagens "qualitativas", mas também etnográficas, que pressupõem a ida do pesquisador ao campo e seu estabelecimento de relaçôes pessoais com os sujeitos, por meio da participação direta na vida cotidiana e no meio cultural deles. A própria Organização Mundial de Saúde, ao avaliar as diferentes metodologias utilizadas no estudo do uso de psicoativos, considera a etnografia e os métodos similares entre os mais eficientes quanto à relação custobenefício, entendendo-se este último como uma maior quantidade e qualidade de informações (Romaní, 1999, p. 155).

Portanto, não há como deixar de empregar métodos qualitativos, que já há muito vêm sendo utilizados e aperfeiçoados não só em estudos realizados primariamente no âmbito das ciências sociais, mas também no de certas disciplinas biomédicas como a saúde pública e a saúde coletiva. Técnicas como entrevistas em profundidade - abertas, semi-estruturadas ou fechadas -, discussões em grupo, história de vida, observação participante e etnografias são as que permitem o estudo das interaçôes sociais e dos processos interpretativos e simbolizantes, por meio dos quais a realidade é constituída e apreendida culturalmente.

Especialmente importante aqui é a observação participante em suas diversas modalidades, o método emblemático da antropologia e o que mais exige interação prolongada e aprofundada entre pesquisador e pesquisado in situ. Ao realizá-la, o pesquisador deve, na medida do possível, procurar despojar-se dos signos mais denunciadores de sua alteridade, aprendendo a linguagem e as normas comportamentais vigentes no grupo estudado. Nessa empreitada, ele não só deve voltar sua 
atenção às concepções e opiniōes dos sujeitos (também captáveis em entrevistas), mas contextualizar essas verbalizações em relação aos comportamentos observados.

Sujeita a muitas críticas dos defensores dos padrões biomédicos, que a consideram demasiadamente subjetiva e imprecisa, a observação participante pressupóe, porém, a adoção de uma multiplicidade de técnicas, várias das quais bastante precisas. Além disso, a manutenção de um diário de campo durante a pesquisa é poderoso aliado no reforço do senso de alteridade dos pesquisadores perante seus sujeitos de estudo.

Mais do que servir para comprovar a atuação de variáveis definidas previamente em abstrato, a observação participante é especialmente indicada para a exploração de um determinado campo, para a descrição de uma cultura e sua organização, e para a identificação de problemas ou questóes a serem estudados em maior detalhe. Assim, projetos de pesquisa que investigam os aspectos culturais do uso de drogas e adotam métodos antropológicos, especialmente a observação participante, geralmente causam estranheza e até rejeição entre cientistas de outras disciplinas, como as da saúde, uma vez que muitas vezes não apresentam hipóteses formuladas a priori a serem testadas.

Fonte de igual incompreensão é a questão da "amostragem", normalmente considerada, pelos critérios da biomedicina e de outras ciências, fundamental para assegurar a significância estatística e a validade de uma pesquisa. Não se levam em conta os inúmeros contatos informais, mas de grande potencial informativo, que o pesquisador trava com os múltiplos atores no campo de pesquisa. Além disso, observações ou entrevistas feitas em campo, sob a operação das forças sociais normalmente operantes, são muito mais fidedignas do que as realizadas em situaçóes mais controladas, nos quais os sujeitos pesquisados ficam mais suscetíveis à influência do pesquisador (cf. Becker, 1993, pp. 68-77). 


\section{As dificuldades trazidas às pesquisas antropológicas pela Resolução 196/96}

Atualmente novas dificuldades vêm sendo apresentadas não somente para a realização de pesquisas de campo voltadas para o uso de substâncias psicoativas, mas para grande parte dos estudos de cunho antropológico ou sociológico em geral. É muito necessário que os cientistas sociais, especialmente aqueles cujos temas de estudo fazem interface com áreas de saúde, atentem para os debates que ocorrem em torno da ética nas pesquisas antropológicas, especialmente com relação à Resolução 196/ 96, instituída pela Comissão de Ética em Pesquisa do Ministério da Saúde para regular os aspectos éticos de pesquisas que envolvem humanos.

O problema é que essa resolução parece ter sido concebida com o propósito central de proteger os sujeitos envolvidos em pesquisas de natureza biomédica por meio da instituição de uma série de formalidades que as rejam. Mas, devido à costumeira generalização dos valores e padrões da biomedicina para todas as outras disciplinas científicas, essas estipulaçôes foram estendidas a outras áreas de estudo, como a antropologia, passando a ameaçar a plena utilização de alguns de seus métodos, como a observação participante em inúmeras situações, especialmente entre populaçôes ocultas.

Essa nova situação tem preocupado a própria Associação Brasileira de Antropologia (ABA), que vem debatendo a ética de sua disciplina em diversos fóruns. Em uma publicação editada pela $A B A$, versando sobre o tema, Luis Roberto Cardoso de Oliveira, após criticar o que chama de "biocentrismo" da Resolução 196/96, aponta para o fato de ela ignorar a diferença entre pesquisas em seres humanos (caso da área biomédica) e com seres humanos (a situação da antropologia, especialmente da social ou cultural). Nas pesquisas em seres humanos, a relação com os sujeitos, objetos das pesquisas, teria como paradigma uma situa- 
Revista de Antropologia, São Paulo, USP, 2006, v. 49 no 2.

ção de intervenção em que seres humanos seriam colocados na situação de cobaias. Nesse caso, procedimentos como a obtenção de consentimento informado do sujeito da pesquisa seriam exigências legítimas e da maior importância. Já no caso de pesquisa com seres humanos, o sujeito do estudo não é cobaia ou objeto de intervenção e, sim, ator ou sujeito de interlocução. Oliveira também ressalta que, na antropologia e no trabalho de campo antropológico, o próprio objeto de pesquisa é negociado: tanto no plano da interação com os atores, como no plano da construção ou definição do problema pesquisado pelo antropólogo (Oliveira, 2004, p. 34).

Outra maneira de formular essa idéia é a de Carlos Caroso (2004), que diz que nas ciências da saúde os sujeitos da pesquisa são concebidos como "seres humanos", atentando-se fortemente para a preservação de seu bem-estar biológico e individual. Já na antropologia seriam concebidos como "pessoas" (isto é, entidades basicamente socioculturais), o que demandaria outras concepções sobre ética, uma vez que os antropólogos não interferem nos corpos, mas buscam entender as concepçôes a respeito deles usando observação e entrevistas. Os princípios éticos que os antropólogos vêm desenvolvendo ao longo da existência de sua disciplina têm tido como parâmetros fundamentais a tradição de respeito pelas pessoas e pelos grupos humanos, por seus costumes, comportamentos e práticas, pela diferença, pela alteridade (Caroso, 2004, p. 141).

Ainda na década de 1980, os antropólogos brasileiros já haviam começado a sentir a necessidade de maiores debates sobre o tema que resultassem na instituição de diretrizes normativas para seu trabalho. Assim, a Associação Brasileira de Antropologia (ABA) elaborou um Código de Ética no final daquela década, alinhando de forma sucinta os direitos dos antropólogos enquanto pesquisadores, os direitos das populações que são objetos de pesquisas a serem observados por estes, e, 
Edward MacRae \& Sergio Souza Vidal. A Resolução 196/96...

finalmente, as responsabilidades mais gerais dos antropólogos. Considerava-se que a $\mathrm{ABA}$, cuja consolidação enquanto associação profissional ocorrera em meio a diversas lutas em prol dos Direitos Humanos durante o período seguinte à implantação de um sistema democrático, apresentava aí, de forma sucinta, parâmetros que ajudassem os antropólogos em seus dilemas éticos a se manterem coerentes com o histórico de sua associação. Perante a variedade dos problemas específicos que surgiam, não era viável a elaboração de normas rigidamente detalhadas que pudessem cobrir adequadamente todos os dilemas éticos a serem enfrentados pelos antropólogos. Assim, é significativo o sexto item elencado entre os direitos do antropólogo pelo Código de Ética da ABA, que explicita:

Os direitos dos antropólogos devem estar subordinados aos direitos das populações que são objeto de pesquisa e têm como contrapartida as responsabilidades inerentes ao exercício da atividade científica.

Esse dispositivo claramente invoca normatizações mais gerais que inscrevem as açôes do antropólogo no campo da cidadania, no que se refere às suas responsabilidades em relação aos povos estudados, assim como o enquadram nas regras amplas, gerindo atividades científicas nas quais, em geral, estariam implícitas considerações de ordem metodológica e epistemológica mais amplas a reger o pesquisador em sua busca da verdade.

Porém, nem no código de ética da ABA nem na coletânea Antropologia e ética - o debate atual no Brasil, editada em 2004 sob os auspícios dessa associação, abordam-se mais diretamente as peculiaridades inerentes ao estudo de populaçóes ocultas em geral e de usuários de substâncias psicoativas em específico. 
O código de ética é um documento que parece abarcar os principais aspectos do fazer antropológico de forma genérica, breve e enxuta. Não existem nele referências a nenhuma subárea de pesquisa antropológica, tal como religião, gênero, etnia ou saúde. Porém, o livro de debates editado posteriormente, em que os problemas éticos são discutidos de maneira mais pormenorizada, mesmo ao abordar certos aspectos dos trabalhos com populaçóes ocultas (como pessoas vivendo com HIV), também não se aprofunda em questões de maior importância para pesquisadores de atividades ilícitas.

Assim, não há discussão, por exemplo, sobre maneiras eficazes de proteger o anonimato dos sujeitos desse tipo de pesquisa em relação a exigências policiais ou ao enfocar a demanda de que salvaguardas análogas ao respeito pelo sigilo médico (importante nas pesquisas biomédicas) sejam estendidas às pesquisas antropológicas. Ao se ler relatos sobre estudos de usuários de substâncias ilícitas, depara-se comumente com as difíceis estratégias elaboradas pelos pesquisadores para manter suas anotações, entrevistas, etc. a salvo de ações da polícia. O próprio Becker (1963) já comenta sobre a quase inevitabilidade do pesquisador de comportamentos desviantes acabar, ele mesmo, infringindo certas leis.

A partir de 8 de outubro de 2006, entrou em vigor uma nova legislação sobre drogas em substituição à antiga Lei 6368/76. Embora ainda sujeita a muitas críticas devido ao teor proibicionista, a nova Lei $11343 /$ 06 traz inovaçōes que ajudam a diferenciar o usuário eventual do traficante, instituindo um tratamento mais brando para o primeiro. Infelizmente ela ainda mantém, no capítulo que trata dos crimes, no artigo 33 , no parágrafo 2 , a penalização para quem "induzir, instigar ou auxiliar alguém ao uso indevido de droga". Dada a arbitrariedade que costuma imperar no tratamento policial e até judicial da questão das drogas, é possível que essa disposição seja utilizada para ameaçar autores de pesquisas sobre usuários de drogas ilícitas que venham a adotar uma 
Edward MacRae \& Sergio Souza Vidal. A Resolução 196/96...

postura metodológica tolerante ou compreensiva em relação às práticas de seus sujeitos de estudo.

Infelizmente até agora os antropólogos permanecem sem uma orientação da sua associação sobre como agir em ocasiões em que os interesses de seus sujeitos entram em conflito com a lei. Mesmo a Resolução 196/96, com todos os pormenores, não aborda especificamente essa questão legal no capítulo III, na cláusula $3^{a}$, em que coloca como exigência "prever procedimentos que assegurem a confidencialidade e privacidade, a proteção da imagem e a não-estigmatização, garantindo a não utilização das informações em prejuízo das pessoas e/ou das comunidades inclusive em termos de auto-estima, de prestígio e/ou econômico financeiro".

Em seu artigo publicado na coletânea Antropologia e ética, Guita Debert se refere à necessidade de um código de ética que defenda o pesquisador e a comunidade científica em casos nos quais se busque explorar o potencial da pesquisa antropológica para entender a lógica a partir da qual os grupos mais poderosos operam, em alguns casos de maneira a provocar nossos sentimentos mais fortes de indignação. Essa é uma situação freqüente na pesquisa entre usuários de drogas quando, por exemplo, se constatam atitudes discriminatórias contra membros desse segmento populacional entre entrevistados que são funcionários de instituições públicas oficialmente designados para lhes prestar assistência. Similarmente, qual o grau de lealdade devido a sujeitos de pesquisa cujas atividades, como traficantes, por exemplo, incluem atos de violência ou outras condutas atentatórias aos valores democráticos ou aos Direitos Humanos? São questões complexas, nas quais o antropólogo não dispõe de muitas orientações para embasar suas consideraçôes no momento de fazer suas opções éticas.

As disciplinas da antropologia e da história vêm desenvolvendo um rico diálogo que talvez pudesse ser detectado já no século XIX, quando 
os evolucionistas culturais estudavam povos contemporâneos considerados "primitivos" com a intenção de reconstruir períodos da história da humanidade sobre os quais havia pouca informação direta. Atualmente, registros antigos de cunho antropológico a respeito de tradições populares, grupos étnicos em processo de rápida transformação cultural etc. são concebidos como de muita utilidade para historiadores.

No presente, diversos antropólogos, tomando como modelo a atuação de antropólogos que nas décadas de 1930 e 1940 ajudaram a demonstrar a legitimidade de casas de candomblé ou umbanda, procuram fundamentar as reivindicações por reconhecimento e proteção oficial dos seguidores das religiōes usuárias do chá psicoativo ayahuasca. Essas religiôes estão ainda em fase de consolidação de suas práticas e doutrinas, e antropólogos vêm registrando esse processo de forma detalhada, especificando nomes e localidades, cientes da importância historiográfica de seus testemunhos. Porém, as exigências de anonimato dos sujeitos de pesquisa impostas pela Resolução 196/96 podem desautorizar essas práticas ou lhes impor sérias distorções. Como exemplo cito o caso de um antropólogo que, ao estudar o caso quase único de uma mulher que lidera um grupo desses, sentiu a necessidade de ocultar seu sexo como única maneira de manter seu anonimato. Conseqüentemente, deixou de registrar um importante fenômeno de contestação dos papéis de gênero tradicionais entre os seguidores dessa religião, empobrecendo o valor historiográfico de seu estudo. Ressalte-se que a pesquisa em caso não fazia nenhuma revelação especialmente desabonadora sobre essa pessoa ou sua organização.

Outro sério empecilho que a Resolução 196/96 coloca para os estudos realizados entre populaçóes ocultas em geral, e com impacto especialmente forte sobre as que lidam com usuários de psicoativos, referese à exigência de que "toda pesquisa se processe após consentimento livre e esclarecido dos sujeitos, indivíduos ou grupos que por si e/ou por seus 
Edward MacRae \& Sergio Souza Vidal. A Resolução 196/96...

representantes legais manifestem a sua anuência à participação na pesquisa". Essa disposição é seguida de numerosas especificações, algumas bastante detalhadas e, no caso do tipo de estudo discutido aqui, pouco realistas e difíceis de implementar.

Todo antropólogo sabe, por exemplo, do tato e da delicadeza necessários para se ingressar no campo. Aspectos como a sua aparência, quem são seus primeiros interlocutores, quem o apresentou ao grupo etc. são de grande importância para determinar o tipo de relação que o pesquisador poderá vir a desenvolver com seus sujeitos. Comumente o antropólogo, antes mesmo de iniciar seu trabalho de maneira sistemática, faz algumas visitas ao que pode vir a ser seu campo, buscando avaliar a viabilidade e o rendimento que poderá vir a ter seu estudo, assim como negociar a sua maneira de inserção. Muitos costumam registrar suas primeiras impressóes em cadernos de campo, e talvez até tirem algumas fotografias ou façam gravações em áudio e vídeo. Afinal, considera-se que o registro das primeiras impressões de um novo campo, quando o sentimento de alteridade ainda é muito agudo, pode auxiliar em reflexões posteriores, ressaltando aspectos que passam despercebidos dos "nativos" ou até de um pesquisador que já tenha internalizado parcialmente as suas categorias ou formas de percepção. Embora os antropólogos possam considerar essas preliminares como simples "visitas ao campo", em termos estritos trata-se de um início de pesquisa que, segundo a Resolução 196, deveria ser precedido da obtenção do consentimento.

Imagine as dificuldades e incompreensões que possam ocorrer quando um antropólogo, estudando pessoas em situação de rua, usuários de drogas ilícitas como cocaína injetável, por exemplo, for pedir-lhes que assinem ou coloquem sua impressão digital em um documento de qualquer natureza. É, portanto, completamente irrealista esperar que ele obtenha esse tipo de permissão antes mesmo de começar a fazer contatos mais intensos e freqüentes que sirvam para estabelecer um míni- 
Revista de Antropologia, São Paulo, USP, 2006, v. 49 no 2.

mo de confiabilidade em sua pessoa, como recomenda o capítulo IV da Resolução.

Mesmo pesquisas concebidas e realizadas no âmbito de instituições biomédicas acabam não cumprindo a letra de todas as disposiçōes da Resolução. Um exemplo parece ser o Projeto Ajude-Brasil: Avaliação Epidemiológica dos Usuários de Drogas Injetáveis dos Projetos de Redução de Danos (PRD) Apoiados pela CN-DST/AIDS, realizado em 1998 com o apoio do próprio Ministério da Saúde.

Nesse caso, o consentimento informado, devidamente aprovado por um comitê de ética da UFMG, apresentado aos usuários antes de serem entrevistados, deixava de cumprir todos os pré-requisitos estipulados na Resolução ao não apresentar a justificativa e os procedimentos a serem utilizados na pesquisa, os desconfortos e riscos possíveis e benefícios esperados, os métodos alternativos existentes, as formas de ressarcimento das despesas decorrentes da participação na pesquisa, e as formas de indenização diante de eventuais danos decorrentes da pesquisa (Caiafa, 2001, p. 291).

No caso de entrevistas com criminosos, muitas vezes procurados pela polícia, como traficantes de drogas, parece surrealista pedir que assinem ou forneçam identificação datiloscópica em um documento atestando seu consentimento livre e esclarecido. Mesmo nos casos em que pesquisadores muito hábeis têm conseguido documentos desse tipo, isso só se dá após uma longa permanência no campo e muitas vezes com o entendimento de que o entrevistado vá utilizar uma assinatura falsa - procedimentos que parecem contrariar a letra da Resolução.

Essas são algumas das dificuldades encontradas especificamente no estudo de populaçóes ocultas. Outros pesquisadores, como Luís Roberto Cardoso de Oliveira, já apontaram a inadequação mais geral para a antropologia do conceito de consentimento esclarecido, tal como expresso na Resolução 196. Segundo ele, a própria inserção no campo é algo 
Edward MacRae \& Sergio Souza Vidal. A Resolução 196/96...

que o antropólogo deve negociar, tornando seus diálogos posteriores com os atores consentidos por definição. Ele também aponta para peculiaridades do trabalho do antropólogo, que freqüentemente redefine seus objetivos quando sua pesquisa está em andamento ou talvez quando já tenha até deixado o campo, utilizando então declarações ou observações colhidas de forma distinta do planejado originalmente. Essa flexibilidade tem sido importante para a realização de bons estudos antropológicos, e Oliveira pondera não ser possível, nem desejável, que o antropólogo possa definir ou prever com precisão todos os seus interesses (presentes e futuros) de pesquisa no momento recomendado pela Resolução 196 para a obtenção do consentimento informado (Oliveira, 2004, p. 34).

No campo de estudos sobre usuários de psicoativos, é comum os dados colhidos por diferentes projetos de pesquisa serem reexaminados e utilizados com objetivos diferentes dos iniciais - um bom exemplo disso é o seminal estudo de Howard Becker sobre a carreira do maconheiro (Solomon, 1966) ou a pesquisa de Norman Zinberg sobre o uso controlado de drogas (Zinberg, 1984). O primeiro, além das pesquisas que ele mesmo realizava com usuários de Cannabis, incorporou também entrevistas cedidas por colegas que, desenvolvendo outros estudos com usuários de opióides, também haviam levantado algum material sobre o uso daquela substância. Zinberg, por sua vez, ao escrever seu livro sobre o "uso controlado" de maconha, psicodélicos e opiáceos, incorporou dados de natureza "quali-quanti" levantados em dois projetos diferentes: um financiado pelo Drug Abuse Council em 1973, que visava primordialmente desenvolver técnicas de pesquisa entre usuários daquelas três substâncias, e outro realizado em 1976 com financiamento do National Institute on Drug Abuse, enfocando exclusivamente "usuários controlados" de opiáceos (id., pp. 46-52). 
A Resolução 196/96 preconiza que a pesquisa em qualquer área do conhecimento que envolve seres humanos deverá "ser adequada aos princípios científicos que a justifiquem e com possibilidades concretas de responder a incertezas", e "ser realizada somente quando o conhecimento que se pretende obter não possa ser obtido por outro meio" (Resolução 196/96, capítulo III, parágrafo 3a e 3c). Essa disposição dá margem para o Comitê de Ética em Pesquisa (CEP) que vier a julgar o projeto também opinar sobre a metodologia a ser utilizada, o que poderia vir a inibir a adoção de técnicas novas ou, naquele momento, consideradas adequadas somente para outro tipo de pesquisa. Embora os Comitês de Ética em Pesquisa devam ser de composição multidisciplinar, já vimos como no caso de pesquisas sobre o uso de psicoativos prevalecem os padrões e critérios da biomedicina, considerados como mais "científicos", "objetivos" etc. do que os das ciências sociais. Assim, ingerências dogmáticas de ordem metodológica tornam-se bastante prováveis nos projetos de natureza socioantropológica que vierem a ser submetidos a comitês desse tipo. A atual concentração de CEPs em instituições biomédicas só vem a reforçar esse tipo de inquietação.

Atualmente, as instituições voltadas fundamentalmente ao estudo e à pesquisa das ciências sociais ainda não se adequaram às normas propostas pela Resolução 196, das quais poucos de seus professores ou pesquisadores tomaram conhecimento. Como ocorre com freqüência em relação às políticas públicas, entre diferentes Ministérios existem fortes divergências quanto às fronteiras de suas áreas de atuação. Alguns alegam que não caberia ao Ministério da Saúde e sim ao Ministério da Ciência e Tecnologia a normatização de pesquisas em geral, devendo-se aquele se restringir ao âmbito das pesquisas em seres humanos. A movimentação da $\mathrm{ABA}$ em torno do tema, promovendo seu debate em reuniōes científicas e por meio de publicações, é indício de uma mobilização 
Edward MacRae \& Sergio Souza Vidal. A Resolução 196/96...

dos que se opõem à implementação das disposições da Resolução 196/ 96 em sua forma atual.

O termo "pesquisa envolvendo seres humanos", utilizado na Resolução 196/96 para designar o campo das atividades que visa cobrir, é demasiadamente genérico, englobando, como já apontou Oliveira, pesquisas realizadas com e em seres humanos e se estendendo às mais diversas disciplinas científicas com suas variadas abordagens e metodologias, que implicam importantes diferenças no grau de poder e influência; e, conseqüentemente, responsabilidade do pesquisador em relação aos sujeitos de estudo. Afortunadamente, o próprio documento do Ministério da Saúde prevê, em seu preâmbulo, revisões periódicas segundo necessidades das áreas tecnocientíficas e ética. Conforme apontado, até pesquisas como as do Ajude-Brasil, patrocinada pelo próprio Ministério da Saúde, não parecem cumprir à risca certos quesitos da Resolução, como os relacionados ao consentimento livre e esclarecido. Isso já indica a urgência de se promover reformulações até para adequar o documento às necessidades das áreas biomédicas. Mesmo em se resolvendo manter um documento único para dispor sobre as normas éticas a regerem pesquisas, seria imprescindível propor formulações que atendessem melhor à diversidade das atividades envolvidas.

Por outro lado, a própria ABA vem se movimentando desde a década de 1980 para melhor adequar suas normas éticas aos novos problemas que vão se apresentando concomitantemente às mudanças que ocorrem na sociedade em geral e no campo de atuação dos antropólogos em específico. Assim, não parece ser justificado delegar as deliberações sobre questôes desse teor, deixando-as a cargo de profissionais de outras áreas menos familiarizados com as especificidades da antropologia.

Espera-se que futuramente o código de ética proposto pela ABA possa ser reformulado para contemplar, entre outras questões, as especificidades da pesquisa entre populações ocultas, incluindo usuários e trafican- 
tes de drogas. Mas se deve também evitar a criação de mais obstáculos burocráticos que venham desnecessariamente dificultar e atrasar o trabalho de pesquisadores, já bastante castigados pelo volume diminuto de recursos financeiros, especialmente aqueles que fazem interface com áreas de saúde disponíveis, e por prazos de execução que, apesar de muitas vezes serem pouco adequados às especificidades dos diferentes temas de estudo, estão sendo aplicados de maneira bastante inflexível.

Para finalizar, cabe alertar para a futilidade inerente à tentativa de realizar o que Giddens denomina de "colonização do futuro", bastante difundida atualmente, quando se procura prever e prevenir qualquer risco que possa vir a se apresentar na busca por uma inatingível segurança absoluta.

\section{Notas}

1 Doutor em Antropologia Social pela USP; pesquisador associado do Centro de Estudo e Terapia do Abuso de Drogas (CETAD/UFBa); representante do Ministério da Cultura no Conselho Nacional Antidrogas (CONAD); vice-coordenador da Câmara de Assessoramento Técnico-Científico do CONAD (CATC/CONAD); líder do Grupo Interdisciplinar de Estudos sobre Substâncias Psicoativas (GIESP/ UFBa); pesquisador do Núcleo de Estudos Interdisciplinares sobre Psicoativos (NEIP).

2 Estudante vinculado ao GIESP/UFBa; membro do NEIP. 


\section{Bibliografia}

ALMEIDA-FILHO, N.

1993 "A clínica, a epidemiologia e a epidemiologia clínica", Physis. Revista de Saúde Coletiva, v. 1(3): 33-54.

APA (Americam Psychiatric Association)

Diagnostic and Statistical Manual of Disorders, 3.ed. Revised, Washington, DC, American Psychiatric Association.

BECKER, H. S.

1963 Outisiders - Studies in the Sociologie of Deviance, New York, The Free Press.

1993 Métodos de pesquisa em Ciências Sociais, São Paulo, Hucitec.

CAIAFA, Waleska.

2001

Projeto Ajude-Brasil: Avaliação Epidemiológica dos Usuários de Drogas Injetáveis dos Projetos de Redução de Danos Apoiados pela CN-DST/AIDS, Brasília, Ministério da Saúde.

CARLINI, E. A. et al.

2001 I Levantamento Domiciliar sobre o Uso de Drogas Psicotrópicas no Brasil, São Paulo, CEBRID/UNIFESP.

CAROSO, Carlos

2004 "A imagem e a ética na encruzilhada das ciências", in VICTORIA et. al. (orgs.), Antropologia e ética: o debate atual no Brasil, Niterói, Editora da Universidade Federal Fluminense, pp. 137-50.

DEBERT, Guita Grin

2004

"Ética e as novas perspectivas da pesquisa antropológica", in VICTORIA et al. (orgs.), Antropologia e ética: o debate atual no Brasil, Niterói, Editora da Universidade Federal Fluminense, pp. 45-54.

LIMA, Élson da Silva; BAPTISTA, Marcos; INEM, Clara.

1997 Toxicomanias - abordagem multidisciplinar, Rio de Janeiro, NEPAD/UERJ, pp. 91-100. 
Revista de Antropologia, São Paulo, USP, 2006, v. 49 no 2.

MINAYO, Maria Cecília de Souza

1999 O desafio do conhecimento - pesquisa qualitativa em saúde, 6.ed., São Paulo, Hucitec/Abrasco.

OLIVEIRA, Luís Roberto Cardoso de

2004 "Pesquisa em versus pesquisa com seres humanos", in VICTORIA et al. (orgs.), Antropologia e ética: o debate atual no Brasil, Niterói, Editora da Universidade Federal Fluminense, pp. 33-44.

ROMANÍ, Oriol

1999 Las drogas - sueños e razones, Barcelona, Ariel.

SAMHSA (Substance Abuse Mental Health Services Administration)

1996 Substance Abuse in States and Metropolitan Areas: Model Based Estimates from 1991-1993, National Household Survey on Drug Abuse: Summary Report, US Department of Health and Human Services.

1999 Office of Applied Studies: 1998, National Household Survey on Drug Abuse, US Departament of Health and Human Services.

SOLOMON, D. (org.)

1966 The Marijuana Papers, New York, The Bobbs-Merril Company Inc.

ZINBERG, Norman

Drug, Set and Setting - The Basis for Controlled Intoxicant Use, New York, Yale University Press. 
ABSTRACT: The Resolution 196/96, which the Ministry of Health instituted with the aim of regulating the ethical aspects of all research "involving human beings", has not yet been duly appreciated in all its implications for anthropological research. This article points out the difficulties that this Resolution presents to fieldwork, especially in relation to the study of illicit activities such as the use of psychoactive substances. Such studies frequently take the form of ethnographies and presuppose going to the field and establishing personal relations with the subjects through a direct participation in their daily activities and in their culture.

This methodology and the illicitness of the activities under study require specific ethical considerations which are not met by the Resolution. Some of the problem areas are: (a) The need of approval for the project by a Committee of Ethics; (b) The difficulties in obtaining informed consent when working among hidden populations; (c) The abetting or apology of illegal acts; (d) The difficulty in doing social criticism without hurting the interests of any of the subjects under study; (e) The maintenance of anonymity in studies that might also be historical records.

The specificities of the different disciplines strengthen the notion that Committees of Ethics ought to be sectional so as to avoid judging all questions according to standards which are only appropriate to some of them.

KEY-WORDS: ethics, hidden populations, psychoactive substances, fieldwork, ABA. 